Review

\title{
Lower-Limb Exosuits for Rehabilitation or Assistance of Human Movement: A Systematic Review
}

\author{
Martin Andreas Koch ${ }^{1, *}$ and Josep M. Font-Llagunes ${ }^{2,3}$ (D) \\ 1 ELISAVA Barcelona School of Design and Engineering, 08002 Barcelona, Spain \\ 2 Biomechanical Engineering Lab, Department of Mechanical Engineering and Research Centre for \\ Biomedical Engineering, Universitat Politècnica de Catalunya, 08028 Barcelona, Spain; josep.m.font@upc.edu \\ 3 Institut de Recerca Sant Joan de Déu, 08950 Esplugues de Llobregat, Spain \\ * Correspondence: mkoch@elisava.net
}

check for updates

Citation: Koch, M.A.; Font-Llagunes, J.M. Lower-Limb Exosuits for Rehabilitation or Assistance of Human Movement: A Systematic Review. Appl. Sci. 2021, 11, 8743. https://doi.org/10.3390/app 11188743

Academic Editor: Philip Fink

Received: 30 August 2021

Accepted: 15 September 2021

Published: 19 September 2021

Publisher's Note: MDPI stays neutra with regard to jurisdictional claims in published maps and institutional affiliations.

Copyright: (c) 2021 by the authors. Licensee MDPI, Basel, Switzerland. This article is an open access article distributed under the terms and conditions of the Creative Commons Attribution (CC BY) license (https:// creativecommons.org/licenses/by/ $4.0 /)$.
Featured Application: This review about clinical and technological aspects of lower-limb exosuits may be useful for engineers and researchers to improve future exosuit designs for rehabilitation and movement assistance. This state-of-the-art overview can be beneficial for evaluating and optimizing exosuit design and test protocols for the benefit of the user.

\begin{abstract}
Background: The aim of this review is to provide a comprehensive overview of the technological state-of-the-art of exosuits and the clinical results obtained when applied to users with mobility impairment. Methods: Searches are carried out in the COCHRANE, PubMed, IEEE Xplore and MEDLINE databases. Titles, abstracts and full texts are screened for inclusion criteria. Technological and clinical data are extracted. The quality of the studies is evaluated via a study quality assessment tool. Results: 19 studies are identified as relevant. Active (47\%) and passive exosuits (53\%) are used. Most are used untethered (84\%), accommodating the demand of mobility. No study reports power consumption, which is important for dimensioning power systems. Fields of applications are post-stroke (79\%), osteoarthritis (16\%) and post-trauma (5\%). Mostly the ankle joint is addressed $(57 \%)$, while less studies address multiple joints $(21 \%)$. The outcomes of clinical evaluations of lower-limb exosuits with patients suffering from mobility impairments are positive in the correction of gait pattern and reducing metabolic energy consumption during hemiparetic walking. Conclusions: Lower-limb exosuits for clinical applications are still facing technological challenges. Fields of application are limited to stroke, osteoarthritis and trauma. While clinical outcomes are overall positive, improvements in the study protocols are suggested.
\end{abstract}

Keywords: exosuit; exoskeleton; rehabilitation; stroke

\section{Introduction}

A wide range of respiratory, cardiovascular, musculoskeletal and neurological diseases can affect mobility [1], impeding various activities of daily living and productive tasks. It has been shown that the ability to walk is likely the mobility factor that influences the physical and mental health-related quality of life the most [1]. An epidemiology study in the USA showed that in 2016 an estimated 61.4 million noninstitutionalized adults reported a disability, with mobility leading as the most prevalent type (13.7\%) [2]. In Europe, about one third (32.3\%) of adults aged 75 years or older and $10.5 \%$ of adults aged $65-74$ years reported severe difficulties in walking [3]. With the increase in the older population, the problem of mobility will become more prevalent. In Europe, for example, in 2050 the number of people aged $75-84$ years is expected to increase by $56.1 \%$ and people aged 65-74 years by $16.6 \%$, compared to 2019 [4].

Given the prevalence of mobility disorders, the foreseen increase in cases due to an aging population and their impact on quality of life, it is of highest interest to rehabilitate or 
assist walking to restore mobility. In recent years, the field of robotics has advanced significantly to assist the recovery of lower-limb motor function [5]. Compared to conventional therapies, rehabilitation robotics allows the alleviation of the work of health care personnel, permits longer rehabilitation sessions for the patient, can be monitored, controlled and quantified reliantly and can provide an increased motivation by use of gamification. Of special interest are robotic lower-limb exoskeletons, which are worn by a user, fit externally to the body and work in coordination with the user's movement [6]. Powered exoskeletons generally have a rigid supporting structure and actuators that assist movement in users who might have little to no remaining motor function in their lower limbs. The nature of their rigid structures and the necessity for a power supply make robotic rigid exoskeletons cumbersome, decreasing their overall functionality and movement range.

To overcome the restrictions of rigid systems, soft exoskeletons (or "exosuits") have been developed, where weight-bearing relies on the user's skeletal structure alone. Exosuits reduce weight and minimize limitations in movement by the use of fabric harnesses and low-profile actuation systems. Their greater flexibility provides a larger tolerance for misalignment with the user's skeletal system compared to rigid exoskeletons [7]. As a result, exosuits may facilitate a more natural interaction with the dynamics of walking [8]. Several exosuit models have been developed and published, e.g., Body Braid [9], Superflex [10] or "ReStore" ${ }^{\mathrm{TM}}$ Soft Exo-Suit" [11]. To gather evidence about the functionality and benefits of exosuits, it is important to provide peer-reviewed studies that show the effects on the impaired user.

General reviews about exoskeletons have been published, mentioning the research in exosuits, but without going into further details on their technological aspects and clinical outcomes $[12,13]$. Several reviews have recently been published that specifically analyze exosuits. For example, Jain et al. [14] show an overview of different technological aspects of exosuits, Crowell et al. [15] review the design challenges for exosuits, Masia et al. [16] provide an in-depth explanation of construction and control schemes of soft assistive robots, while Totaro et al. [17] compare different sensor technologies for exosuits. However, thus far none of the published reviews shows the clinical outcomes of lower-limb exosuits, which are an important indicator for the state of development and foreseeable impact on the health sector.

Given the promising premise of exosuits for restoring mobility and the limited number and extent of reviews available about lower-limb exosuits, the aim of this review is to provide a comprehensive overview of the technological state of the art of these devices and the clinical results obtained when applied to users with mobility impairments.

The following research questions are addressed: (1) What technologies are used in lower-limb exosuits? (2) What are the outcomes of clinical evaluations of lower-limb exosuits with users suffering from mobility impairment? By responding to these questions, this review provides insights into current (i) fields of application, (ii) technologies applied in exosuits, (iii) methods used for controlling and evaluating exosuits and (iv) clinical benefits and shortcomings. These insights are a valuable contribution to the development of future exosuits and the improvement of mobility assistance and rehabilitation.

\section{Methods}

\subsection{Search Strategy}

A search was performed in the electronic databases MEDLINE, PubMed, IEEE Xplore and Cochrane CENTRAL Library. The following search string with Boolean operators was used in the search for articles:

(exoskeleton OR exoskeletons OR exosuit OR exosuits OR orthosis OR orthotics OR frame OR suit) AND (soft OR elastic OR semi-rigid OR flexible) AND (rehabilitation OR enhancing OR enhancement OR activity OR stability OR running OR walking OR gait OR assistance OR stroke OR energy)

Additional studies were identified by reviewing references of relevant articles. 


\subsection{Inclusion and Exclusion Criteria}

In this review, database searches were limited to the following definition. A soft exoskeleton (or exosuit) has no essential rigid structure, is worn by a human user, fits to the body and moves along with the body movement. It adds or aids at least one articulation of the human body and it is focused on the rehabilitation or assistance of movement. Rehabilitation is aimed at the restoration of the ability to move or to fulfill certain tasks, which has been lost due to a pathology or an accident. It does not include immobilization of articulations.

For this definition, active exosuits need an external power input (e.g., electrical power), while passive systems are self-contained, generating the necessary power themselves [18]. In this review, no distinction between a soft exoskeleton and exosuit is made.

Studies were selected by revision of title, abstract and full text. By screening the titles first, articles that did not fall into the category of "exosuits for humans" were excluded. After that, abstracts and full texts were screened for the following inclusion criteria: The study uses a physical prototype or device that (i) is a complete device, (ii) falls into the definition of "exosuit", (iii) is worn by a human user, (iv) is used for clinical rehabilitation or aid of an impaired user, (v) does not use a rigid frame, (vi) does add or aid at least one lower-limb articulation of the human body and (vii) does not block movement of an articulation.

Articles not meeting all criteria were excluded. No restrictions on study design or time of publication were included. Search for relevant studies was ended 31 December 2020. Studies in languages other than English were excluded.

\subsection{Data Extraction}

The full text of all articles that met the inclusion criteria was read and relevant data were extracted. The type of information extracted is listed in Table 1. The extracted information was then transferred into a comprehensive table. For this review, one of the authors created the search and conducted the selection process, while the second author supervised the review process. Both authors created and discussed the inclusion criteria and the technological information to extract.

Table 1. Data extracted for analysis.

Articles Were Scanned for the Following Information:

Year of publication
Body part, articulations addressed
Power type used for the exosuit (active or passive)
Weight of the exosuit
Tethered or untethered use
Actuator type for moving the exosuit
Type of force transmission on body
Control scheme applied
Evaluation methods and tasks performed for evaluation
Technological results
Clinical results

\subsection{Quality Assessment}

The quality of included articles was assessed with a modified version of the Cochrane Quality Appraisal Tool [19]. For each of the 14 quality appraisal criteria (see Table 2), a score of 0 to 1 was allocated, with a maximum score of 14 for high methodological quality. The quality of the articles was scored as poor (0-4 points), fair (5-9 points) or good (10-14 points). The 14 criteria of the assessment tool range from the statement of the research question, population sample size justification, outcome measurements up to the statistical analysis of study outcomes (see Table 2). Non-compliance with most of the defined criteria lowers the scientific quality of the assessed study. 
Table 2. Questions used for the quality assessment.

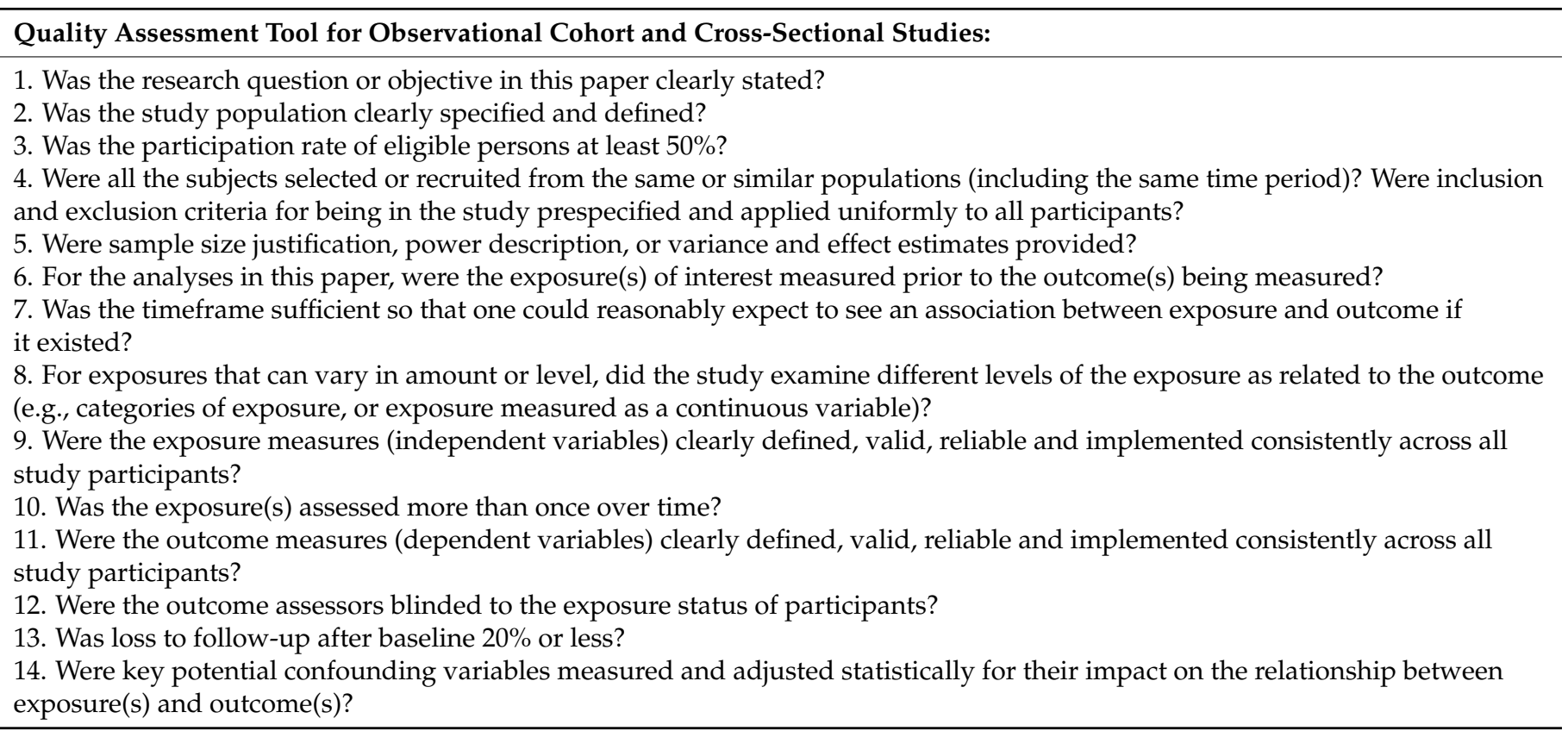

\section{Review}

\subsection{Database Search}

According to the search criteria, 2242 studies in total were identified (see Figure 1). A total of 71 of all found publications were excluded by language. After removing 25 duplicates, 2024 studies were excluded by screening their title and abstract for relevance. Titles were excluded because they referred to topics such as rigid exoskeletons, cell exoskeletons, exoskeletons of insects or even astronomy. From the remaining 212 full text articles, 121 were excluded because the articles were about rigid exoskeletons or simulations without a physical prototype. 


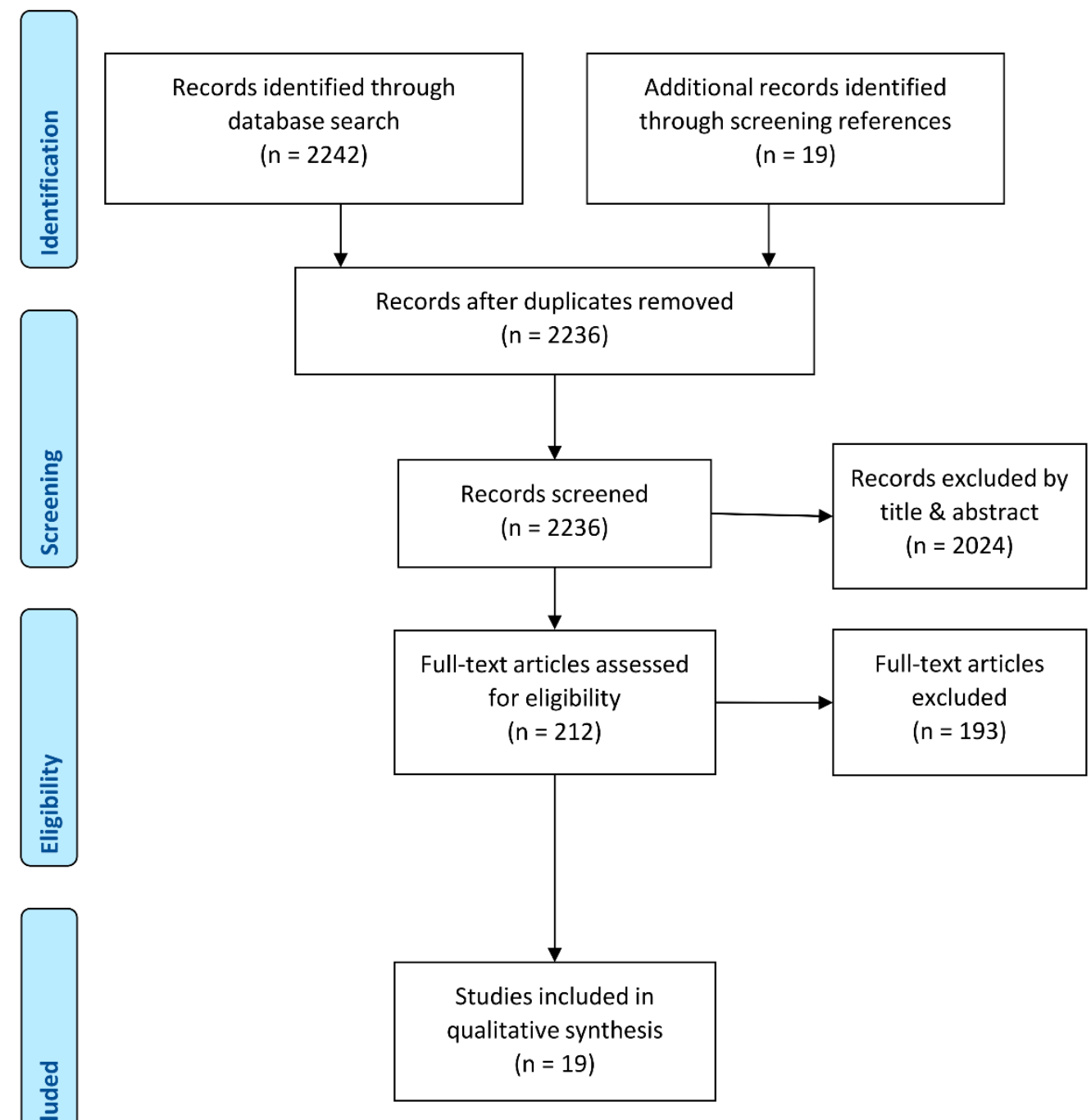

Figure 1. PRISMA flowchart of the article selection process (Modified from Moher et al. [20]).

Of the 72 exosuit studies found, 53 were conducted with healthy subjects and therefore discarded. The remaining 19 studies were included in this review. These studies have been published between 2009 and 2020 (see Figure 2a), where 53\% have appeared in the last 3 years, that is, from 2018 to 2020. Exosuits have gained research interest in recent years, as indicated by the growing number of publications per year. Most studies have emerged recently, even though exosuits have been used at least since the 1970s. Russian cosmonauts used the "Penguin" body-loading suit to combat the effects of low gravity environments on the human body [21,22], which later evolved into the "Regent" exosuit [23]. 


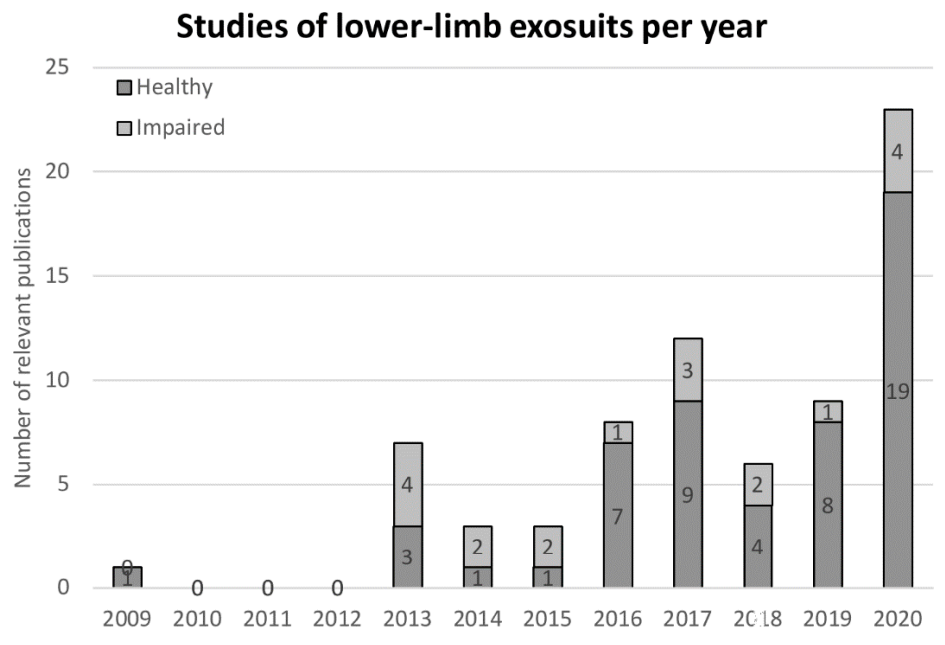

(a)

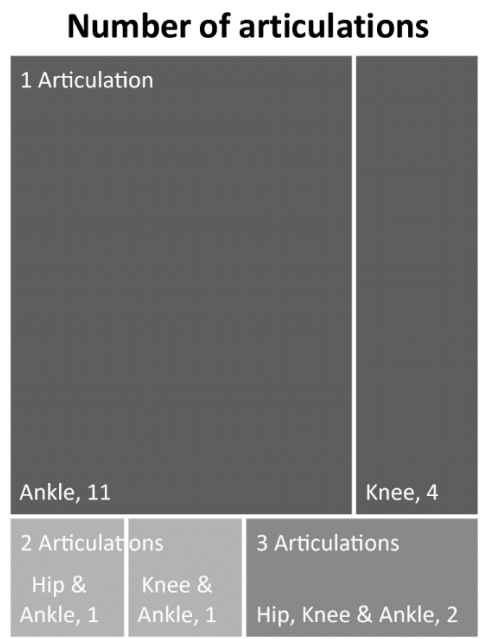

(b)
Actuator types

Pneumatic actuator; $1 ; 11 \%$

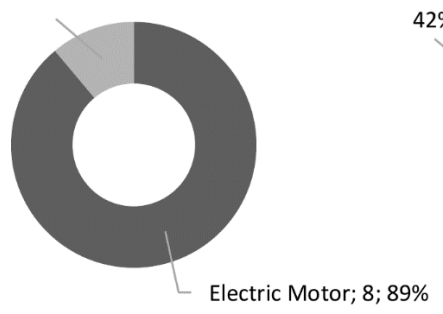

(c)
Force transmission Bowden cable; 8; $42 \%$

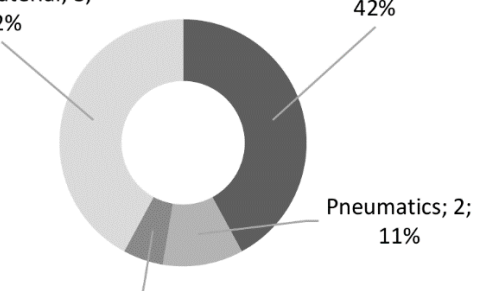

Springs; $1 ; 5 \%$

(d)

\section{Sensor types}

Inertial Measurement Units (IMU) or gyroscopes; $8 ; 42 \%$

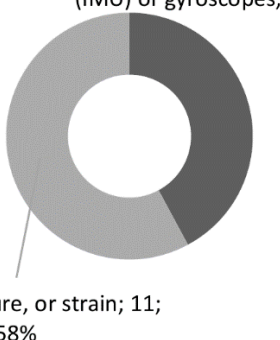

(e)

Number of studies by impairment

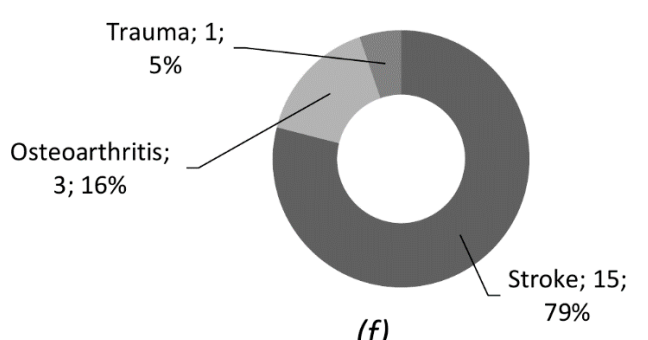

(f)

\section{Number of users by impairment}

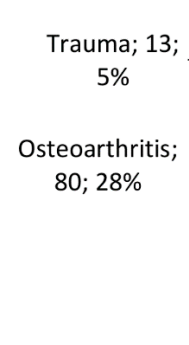

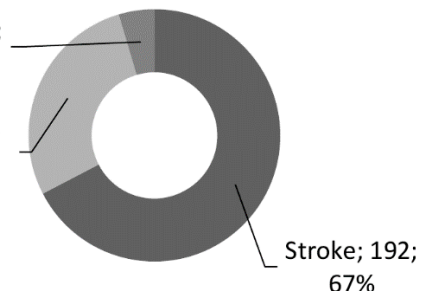

(g)

Figure 2. (a) Number of relevant publications per year, separated by impaired and healthy test subjects; (b) tree map chart of articulations addressed by the exosuits by number of publications; (c) actuator types used for force generation by number of publications; (d) techniques of force translation employed by number of publications; (e) sensor types used for measurement in the exosuits; (f) percentage of studies by impairment; and (g) percentage of users enrolled by different impairments.

\subsection{Quality Assessment}

In quality assessment, 12 articles scored "good", 7 "fair" and none "poor". Overall, a lack of reporting the recruitment process of participants was noted. Especially, the absence of sample size justification and the statement of blinded assessors was common. The calculation of sample size [24], quantitative data about the enrollment process and the definition of the study's target population should be provided for a better reporting quality in future publications [25].

\subsection{Exosuit Technology}

Information of the technological features extracted from the studies is presented in Table 3. Lower-limb exosuits can address any combination of the articulations of hip, knee 
and ankle. Of the identified studies, $21 \%$ addressed two or more articulations. Single articulation studies were the most common ones (79\%), with a focus on ankle (58\%) and knee $(21 \%)$. Figure $2 \mathrm{~b}$ shows the number of studies addressing articulations and their combinations. The complexity of exosuits is influenced by the number of addressed joints and the technical implementation of their control architecture, including sensors and controllers. Examples of levels of complexity are shown in Figure 3. Reviewed studies are mostly focused on single-articulation exosuits, which is explained by the increasing complexity when creating multi-articulation setups. The control of multiple articulations during a movement is difficult to design and the interplay of the exosuit and the user is hard to predict. Considering the rise in interest of the topic and ongoing studies of exosuits, it is foreseeable that with the accumulation of study results, multi-articulation setups are going to become more common.
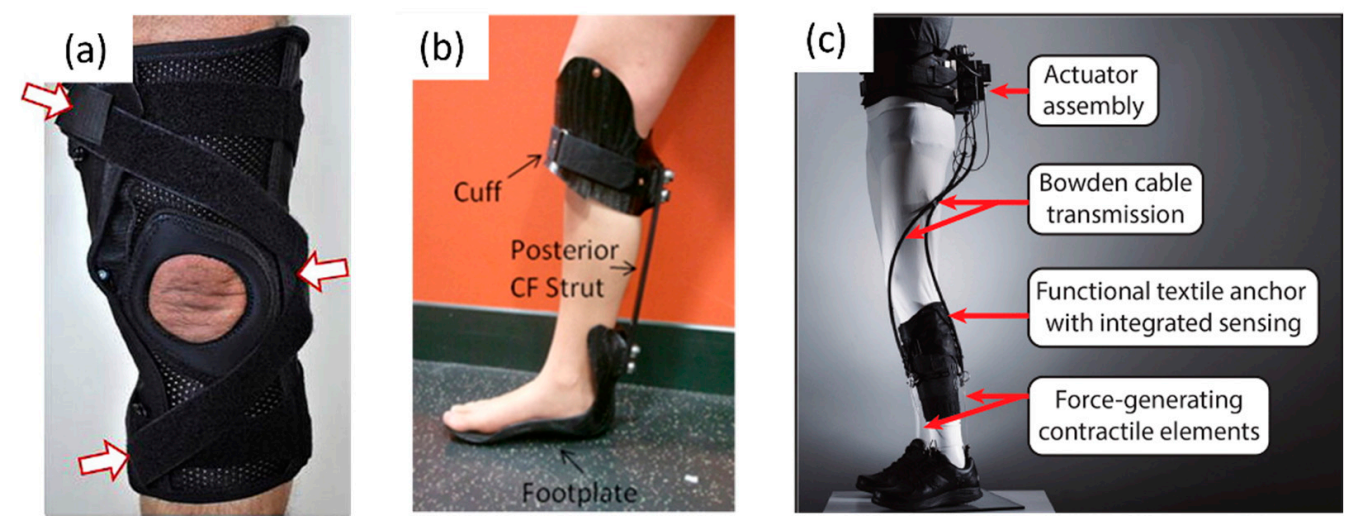

Figure 3. Examples of lower-limb exosuit devices: (a) Passive knee sleeve with pneumatic chambers (reproduced from [26]), (b) passive elastic ankle brace (reproduced from [27]), (c) active ankle assistive exosuit (reproduced from [28]). 
Table 3. Exosuit technological features extracted from the relevant publications.

\begin{tabular}{|c|c|c|c|c|c|c|c|c|c|}
\hline ID & Year & Articulations & Power Type & Weight & $\begin{array}{l}\text { Tethered (T)/ } \\
\text { Untethered (U) }\end{array}$ & Actuators & $\begin{array}{c}\text { Type of Force } \\
\text { Transmission on } \\
\text { Body }\end{array}$ & Sensor Types/Application & Control Scheme * \\
\hline Awad et al. [29] & 2020 & Ankle & Active & $5 \mathrm{~kg}$ & $\mathrm{U}$ & Electric & Bowden cables & $\begin{array}{l}\text { Gyroscope, load cells/Identify } \\
\text { gait events (foot-mounted } \\
\text { gyroscope). Monitor and } \\
\text { adjust applied force on } \\
\text { Bowden cables (load cells). }\end{array}$ & A \\
\hline Awad et al. [28] & 2020 & Ankle & Active & $<5 \mathrm{~kg}$ & $\mathrm{U}$ & Electric & Bowden cables & $\begin{array}{l}\text { Gyroscope, load cells/Identify } \\
\text { gait events (foot-mounted } \\
\text { gyroscope). Monitor and } \\
\text { adjust applied force on } \\
\text { Bowden cables (load cells). }\end{array}$ & A \\
\hline Awad et al. [30] & 2017 & Ankle & Active & $0.9 \mathrm{~kg}$ & $\mathrm{~T}$ & Electric & Bowden cables & $\begin{array}{l}\text { Gyroscope, load cells/Identify } \\
\text { gait events (foot-mounted } \\
\text { gyroscope). Monitor and } \\
\text { adjust applied force on } \\
\text { Bowden cables (load cells). }\end{array}$ & A \\
\hline Awad et al. [8] & 2017 & Ankle & Active & $\begin{array}{c}0.9 \mathrm{~kg} \text { (Tethered)/ } \\
3.19 \mathrm{~kg} \\
\text { (Untethered) }\end{array}$ & $\mathrm{U}$ & Electric & Bowden cables & $\begin{array}{l}\text { Gyroscope, load cells/Identify } \\
\text { gait events (foot-mounted } \\
\text { gyroscope). Monitor and } \\
\text { adjust applied force on } \\
\text { Bowden cables (load cells). }\end{array}$ & A \\
\hline Bae et al. [31] & 2018 & Hip, Ankle & Active & $0.9 \mathrm{~kg}$ & $\mathrm{~T}$ & Electric & Bowden cables & $\begin{array}{l}\text { Gyroscope, load cells/Identify } \\
\text { ground contact events } \\
\text { (foot-mounted gyroscope). } \\
\text { Monitor and adjust applied } \\
\text { force on Bowden cables } \\
\text { (load cells). }\end{array}$ & A \\
\hline $\begin{array}{l}\text { Boudarhan et al. } \\
\text { [32] }\end{array}$ & 2014 & Ankle & Passive & - & $\mathrm{U}$ & - & Elastic material & - & $\mathrm{N}$ \\
\hline Cudejko et al. [33] & 2017 & Knee & Passive & - & $\mathrm{U}$ & - & Elastic material & - & $\mathrm{N}$ \\
\hline Daher et al. [34] & 2013 & Ankle & Passive & - & $\mathrm{U}$ & - & Elastic material & - & $\mathrm{N}$ \\
\hline $\begin{array}{l}\text { Della Croce et al. } \\
{[26]}\end{array}$ & 2013 & Knee & Passive & - & $\mathrm{U}$ & Pneumatic & Air bladder & - & $\mathrm{N}$ \\
\hline Harper et al. [27] & 2014 & Ankle & Passive & - & $\mathrm{U}$ & - & Leaf spring & - & $\mathrm{N}$ \\
\hline Hwang et al. [35] & 2013 & $\begin{array}{l}\text { Hip, Knee } \\
\text { Ankle }\end{array}$ & Passive & - & $\mathrm{U}$ & - & Elastic material & - & $\mathrm{N}$ \\
\hline Kim et al. [36] & 2015 & Ankle & Passive & - & $\mathrm{U}$ & - & Elastic material & - & $\mathrm{N}$ \\
\hline
\end{tabular}


Table 3. Cont.

\begin{tabular}{|c|c|c|c|c|c|c|c|c|c|}
\hline ID & Year & Articulations & Power Type & Weight & $\begin{array}{c}\text { Tethered (T)/ } \\
\text { Untethered (U) }\end{array}$ & Actuators & $\begin{array}{c}\text { Type of Force } \\
\text { Transmission on } \\
\text { Body }\end{array}$ & Sensor Types/Application & Control Scheme* \\
\hline Kwon et al. [37] & 2019 & Ankle & Active & $1.54 \mathrm{~kg}$ & $\mathrm{U}$ & Electric & Bowden cables & $\begin{array}{l}\text { Inertial measurement unit } \\
\text { (IMU), strain sensors, force } \\
\text { sensitive resistors } \\
\text { (FSRs)/Detection of gait phase } \\
\text { via foot-ground contact events } \\
\text { (FSRs). Measurement of knee } \\
\text { and ankle angle (strain } \\
\text { sensors), and shank } \\
\text { angle (IMU). }\end{array}$ & $\mathrm{A}$ \\
\hline Lee et al. [38] & 2016 & Knee, Ankle & Passive & - & $\mathrm{U}$ & - & Elastic material & - & $\mathrm{N}$ \\
\hline $\begin{array}{l}\text { Monticone et al. } \\
\text { [23] }\end{array}$ & 2013 & $\begin{array}{l}\text { Hip, Knee } \\
\text { Ankle }\end{array}$ & Passive & - & $\mathrm{U}$ & - & Elastic material & - & $\mathrm{N}$ \\
\hline Schween et al. [39] & 2015 & Knee & Passive & - & $\mathrm{U}$ & - & Elastic material & - & $\mathrm{N}$ \\
\hline Siviy et al. [40] & 2020 & Ankle & Active & $4.932 \mathrm{~kg}$ & $\mathrm{U}$ & Electric & Bowden cables & $\begin{array}{l}\text { IMUs, load cells/Identify gait } \\
\text { events by foot and shank } \\
\text { movement (IMUs). Monitor } \\
\text { and adjust applied force on } \\
\text { Bowden cables (load cells) to } \\
\text { match force profile. }\end{array}$ & $\mathrm{A}$ \\
\hline Sloot et al. [41] & 2018 & Ankle & Active & $2 \mathrm{~kg}$ & $\mathrm{U}$ & Electric & Bowden cables & $\begin{array}{l}\text { Gyroscope, load cells/Identify } \\
\text { gait events (foot-mounted } \\
\text { gyroscope). Monitor and } \\
\text { adjust applied force on } \\
\text { Bowden cables (load cells). }\end{array}$ & A \\
\hline Sridar et al. [42] & 2020 & Knee & Active & $0.26 \mathrm{~kg}$ & $\mathrm{~T}$ & Pneumatic & $\begin{array}{l}\text { Inflatable } \\
\text { structure }\end{array}$ & $\begin{array}{l}\text { Pressure sensor, shoe insole } \\
\text { sensor/Detect gait phase via } \\
\text { ground reaction forces (shoe } \\
\text { insole sensor). Monitor and } \\
\text { control actuator pressure } \\
\text { (pressure sensor). }\end{array}$ & A \\
\hline
\end{tabular}

* A: Automatic control based on sensor data; N: No control. -: Information could not be determined. 
Studies included in this review used active and passive exosuits ( 9 and 10 studies, respectively). Actuator types used in the active exosuits are electric motors $(89 \%)$ and pneumatic actuators (11\%) (see Figure 2c). None of the publications stated the amount of power consumed by the active exosuits. From all included studies, three used exosuits that had to be tethered to an external power source or air compressor, while 16 were untethered. All passive exosuits were untethered, compared with six out of nine active exosuits. Several types of force transmission were used to transmit displacements and forces from an actuator to the body. Bowden cables and elastic materials were the most frequently used type for force transmission ( $42 \%$ each), followed by pneumatic inflatable structures $(11 \%)$ and springs (5\%) (see Figure $2 \mathrm{~d}$ ). The functionality of an exosuit depends highly on the mechanical components selected to actuate and transmit forces to the body. To transfer movement to the lower extremities during the performance of tasks, particularly Bowden cables and pneumatic actuators are used. Bowden cables stand out as a readily available technology that has been shown to be effective in exosuits [43]. They allow for application with little space and can adapt to complex surfaces. Another material for force transmission in small spaces might be shape memory alloys (SMA). Thin cables of these alloys can be used to act as contracting muscles when applying heat or electricity. In exosuits for lower limbs, no publication was found using this material, while in exosuits for upper limbs, SMA-based actuators have been used already [44,45]. Another material for this application might be an active mechanical metamaterial that can provide soft, bendable "smart matter" [46] that might adapt and actuate in an exosuit.

Main sensor technologies to provide input in active exosuit controllers were (i) force, pressure or strain (11 studies) and (ii) Inertial Measurement Units (IMU) or gyroscopes (8 studies) (see Figure 2e). Studies with passive exosuits did not employ sensors. Sensors for the monitoring of load or position of the addressed articulations are easily available as commercial products and are easy to implement in the active exosuits. The use of sensors with a continuous variable output is preferable because the measured parameters of load, movement or position themselves are continuous during movement. While electroencephalogram (EEG) and electromyography (EMG) measurements are better suited to detect the user's movement intention, in the reviewed publications EMG was only used for clinical assessment. No exosuit used the EMG data as an input for control, most likely because these physiological measurements need an advanced computational analysis.

Control schemes ranged from having an (i) automatic closed-loop control that detected the movement intended by the user and adjusted the actuators accordingly, and (ii) openloop control, where forces and displacements were delivered by stretching or compressing elastic material during movement. All active exosuits used a closed-loop automatic control scheme, while all passive exosuits used no external control. It is preferable to use an automatic control that reacts to the intended movement of the user and adjusts the actuator's force or position accordingly by analyzing sensor input. For the automatic control, the necessary real-time analysis still faces challenges, for example, the use of adequate sensor sampling frequencies, the availability of processing power on low-power wearable devices or reducing the delay due to sensor data packetizing during data transmission [47].

Most studies stated that exosuits must be lightweight, but of the 19 studies included, none using passive exosuits stated their weight (52\% of all studies). Reporting the weight of the studied exosuit should be highly encouraged for future publications because the wearability of exosuits is derived mostly from their reduced weight. The weight of active exosuits, categorized by force transmission type, was the lightest in pneumatic systems (0.26 kg in tethered use) compared to Bowden cable systems (up to $5 \mathrm{~kg}$ untethered). Compared to active rigid exoskeletons with up to $25 \mathrm{~kg}$ [48], active exosuits have a reduced weight, thanks to the lack of a rigid frame. Nevertheless, they rely on electric motors and pneumatic actuators for moving the users' body, which add weight to the exosuit, and their power output and consumption determine the assisting power of actuation and the autonomy of the suit. Actuation systems and power supply units must be dimensioned 
carefully to reduce weight while maintaining function. Even though newer types of actuators and power sources might help to minimize weight even further in the future, the use of passive exosuits or combination of active and passive systems might be considered. While passive systems can only exert a very limited force on the user, they can reduce the metabolic energy expenditure of the user and minimize the power requirements for actuation in human gait [49].

\subsection{Clinical Studies}

For the analysis of clinical outcomes, the data extracted from the studies are presented in Table 4 . The impairments addressed were mostly stroke (15 studies), followed by osteoarthritis (3) and high-impact trauma (1). Overall, 192 users with stroke, 80 with osteoarthritis and 13 recovering from trauma were enrolled (see Figure 2f,g). Active exosuits were only applied in post-stroke patients, while passive exosuits were applied in all impairment types. The application of exosuits in the reviewed studies was limited to correct and assist the movement of users who were still able to walk. The application in users that are unable to walk, such as in spinal cord injury (SCI), was not considered because of the limited assistive joint torque that exosuits can apply. Given the expected increase in the elderly population [1], degenerative musculoskeletal ailments, such as, for example, osteoarthritis, are going to constitute an important field of application for exosuits. Other possible fields of application could be multiples sclerosis or cerebral palsy. While rigid exoskeletons were already applied in these fields [50,51], exosuits were not evaluated with users affected by these impairments in the reviewed studies. As exosuits work in close synchronicity with the human body and are worn over large periods of time, they change load distributions on the musculoskeletal system of the user [52]. No long-term studies were found in this review to evaluate the long-term effects of the application of external forces by exosuits on the joints or bones of subjects with a degenerative disease, such as osteoarthritis or osteoporosis.

Table 4. Clinical data extracted from the relevant publications.

\begin{tabular}{|c|c|c|c|c|c|c|c|}
\hline ID & Impairment & $\begin{array}{l}\text { No. of } \\
\text { Patients }\end{array}$ & Age (Years) & Height (m) & Weight (kg) & Task & $\begin{array}{c}\text { Evaluation } \\
\text { Type }\end{array}$ \\
\hline $\begin{array}{c}\text { Awad et al. } \\
\text { [29] }\end{array}$ & Stroke & 44 & $27-72$ & $1.60-1.88$ & $51.2-113.3$ & $\begin{array}{l}\text { Treadmill walk, } \\
\text { overground } \\
\text { walk }\end{array}$ & $\begin{array}{c}\text { Frequency of } \\
\text { adverse events, } \\
\text { injuries and } \\
\text { device } \\
\text { malfunctions, } \\
\text { custom } \\
\text { questionnaires, } \\
\text { walking speed }\end{array}$ \\
\hline $\begin{array}{c}\text { Awad et al. } \\
\text { [28] }\end{array}$ & Stroke & 6 & $52 \pm 10$ & - & - & $\begin{array}{l}10 \text { MWT, 6-min } \\
\text { overground } \\
\text { walk }\end{array}$ & $\begin{array}{c}\text { Walking speed, } \\
\text { distance, } \\
\text { indirect } \\
\text { calorimetry }\end{array}$ \\
\hline $\begin{array}{l}\text { Awad et al. } \\
\text { [30] }\end{array}$ & Stroke & 8 & $30-67$ & . & - & $10 \mathrm{MWT}$ & Motion capture \\
\hline Awad et al. [8] & Stroke & 9 & $30-67$ & . & - & $10 \mathrm{MWT}$ & $\begin{array}{c}\text { Motion } \\
\text { capture, } \\
\text { indirect } \\
\text { calorimetry }\end{array}$ \\
\hline Bae et al. [31] & Stroke & 7 & $30-56$ & $1.62-1.86$ & $49.4-89.7$ & $\begin{array}{l}\text { 8-min walk on } \\
\text { treadmill }\end{array}$ & $\begin{array}{l}\text { Motion } \\
\text { capture, } \\
\text { indirect } \\
\text { calorimetry, } \\
\text { ground } \\
\text { reaction force }\end{array}$ \\
\hline $\begin{array}{c}\text { Boudarhan } \\
\text { et al. [32] }\end{array}$ & Stroke & 12 & $51 \pm 16$ & $1.71 \pm 0.1$ & $72 \pm 14$ & $10 \mathrm{MWT}$ & $\begin{array}{c}\text { Motion } \\
\text { capture, EMG }\end{array}$ \\
\hline
\end{tabular}


Table 4. Cont.

\begin{tabular}{|c|c|c|c|c|c|c|c|}
\hline ID & Impairment & $\begin{array}{c}\text { No. of } \\
\text { Patients }\end{array}$ & Age (Years) & Height (m) & Weight (kg) & Task & $\begin{array}{l}\text { Evaluation } \\
\text { Type }\end{array}$ \\
\hline $\begin{array}{c}\text { Cudejko et al. } \\
\text { [33] }\end{array}$ & Osteoarthritis & 44 & $65.7 \pm 9.3$ & - & - & $\begin{array}{c}10 \text { MWT, GUG } \\
\text { test, perturbed } \\
\text { and level walk } \\
\text { on treadmill }\end{array}$ & $\begin{array}{l}\text { Self-report } \\
\text { knee pain, } \\
\text { number of } \\
\text { knee instability } \\
\text { episodes, } \\
\text { perceived knee } \\
\text { confidence }\end{array}$ \\
\hline $\begin{array}{c}\text { Daher et al. } \\
\text { [34] }\end{array}$ & Stroke & 10 & $56.8 \pm 13.51$ & - & - & $\begin{array}{l}\text { Walk, balance } \\
\text { test and } \\
\text { sit-to-stand test }\end{array}$ & $\begin{array}{c}\text { Timed up and } \\
\text { go test, Berg } \\
\text { Balance Scale, } \\
\text { Optogait } \\
\text { System }\end{array}$ \\
\hline $\begin{array}{l}\text { Della Croce } \\
\text { et al. [26] }\end{array}$ & Osteoarthritis & 18 & $68 \pm 9$ & $1.73 \pm 0.07$ & $86.1 \pm 14.2$ & 12-m walk & $\begin{array}{c}\text { Motion } \\
\text { capture, } \\
\text { ground } \\
\text { reaction force }\end{array}$ \\
\hline $\begin{array}{l}\text { Harper et al. } \\
\text { [27] }\end{array}$ & Trauma & 13 & $29.4 \pm 5.8$ & $1.8 \pm 0.08$ & $88.2 \pm 10.8$ & $\begin{array}{l}\text { Walk at } \\
\text { self-selected } \\
\text { velocity and } \\
\text { Froude } \\
\text { velocity }\end{array}$ & $\begin{array}{l}\text { EMG, ground } \\
\text { reaction force, } \\
\text { audio cues for } \\
\text { speed } \\
\text { feedback, } \\
\text { motion capture }\end{array}$ \\
\hline $\begin{array}{c}\text { Hwang et al. } \\
\text { [35] }\end{array}$ & Stroke & 15 & $36-70$ & $1.53-1.75$ & $83-46.6$ & $10 \mathrm{MWT}$ & $\begin{array}{l}\text { GAITrite } \\
\text { system }\end{array}$ \\
\hline Kim et al. [36] & Stroke & 10 & $55.7 \pm 8.43$ & $1.67 \pm 0.0654$ & $67.8 \pm 11.66$ & $\begin{array}{l}\text { Balance test } \\
\text { under three } \\
\text { experimental } \\
\text { conditions }\end{array}$ & $\begin{array}{l}\text { Biodex Balance } \\
\text { System, } \\
\text { plantar foot } \\
\text { pressure } \\
\text { system }\end{array}$ \\
\hline $\begin{array}{c}\text { Kwon et al. } \\
\text { [37] }\end{array}$ & Stroke & 1 & 48 & - & - & $\begin{array}{l}\text { Overground } \\
\text { walk }\end{array}$ & $\begin{array}{l}\text { Motion } \\
\text { capture, } \\
\text { ground } \\
\text { reaction force, } \\
\text { Fugl-Meyer } \\
\text { assessment }\end{array}$ \\
\hline Lee et al. [38] & Stroke & 23 & $37-66$ & $1.48-1.78$ & $31-90$ & $10 \mathrm{MWT}$ & $\begin{array}{c}\text { GAITrite } \\
\text { pressure mat }\end{array}$ \\
\hline $\begin{array}{l}\text { Monticone } \\
\text { et al. [23] }\end{array}$ & Stroke & 30 & $60.2 \pm 6.1$ & - & - & $\begin{array}{c}\text { 6-min walk } \\
\text { test, balance } \\
\text { test, Functional } \\
\text { Independence } \\
\text { Measure, } \\
\text { Barthel Index }\end{array}$ & $\begin{array}{c}\text { Oxygen } \\
\text { saturation, } \\
\text { heart rate, } \\
\text { GAITrite } \\
\text { system, Berg } \\
\text { Balance Scale }\end{array}$ \\
\hline $\begin{array}{c}\text { Schween et al. } \\
\text { [39] }\end{array}$ & Osteoarthritis & 18 & $\begin{array}{c}50 \pm 9 \\
\text { (women) } \\
55 \pm 7 \text { (men) }\end{array}$ & $\begin{array}{c}1.66 \pm 0.06 \\
\text { (women) } \\
1.81 \pm 0.08 \\
(\text { men) }\end{array}$ & $\begin{array}{c}62 \pm 6 \\
\text { (women) } \\
87 \pm 16 \text { (men) }\end{array}$ & $10 \mathrm{MWT}$ & $\begin{array}{c}\text { Ground } \\
\text { reaction force, } \\
\text { walking speed } \\
\text { by light } \\
\text { barriers, } \\
\text { questionnaire, } \\
\text { motion capture }\end{array}$ \\
\hline Siviy et al. [40] & Stroke & 6 & $33-62$ & - & 43.9-101.8 & $\begin{array}{l}\text { 3-min walk on } \\
\text { treadmill }\end{array}$ & $\begin{array}{l}\text { Ground } \\
\text { reaction force, } \\
\text { EMG, motion } \\
\text { capture }\end{array}$ \\
\hline Sloot et al. [41] & Stroke & 8 & - & - & - & $\begin{array}{l}\text { 5-min walk on } \\
\text { treadmill }\end{array}$ & EMG \\
\hline $\begin{array}{l}\text { Sridar et al. } \\
\text { [42] }\end{array}$ & Stroke & 3 & $58-74$ & $1.65-1.85$ & $59.2-83.6$ & $\begin{array}{c}\text { Treadmill walk, } \\
\text { TUG }\end{array}$ & $\begin{array}{l}\text { Ground } \\
\text { reaction force, } \\
\text { EMG, motion } \\
\text { capture }\end{array}$ \\
\hline
\end{tabular}


To clinically evaluate lower-limb exosuits, various tasks were performed and monitored, including walking, balancing and activities of daily living. Walking was the most common task performed, including walking for several minutes ( $3 \mathrm{~min}$ [40], $5 \mathrm{~min}$ [7], 6 min $[23,28]$ and 8 min walking [31]), walking at self-selected velocity or Froude velocity [27] (selected based on leg length) and walking for a determined distance of $10 \mathrm{~m}$ (10 MWT) $[8,28,30,32,33,35,38,39]$ or $12 \mathrm{~m}$ [26]. The $10 \mathrm{MWT}$ was the most common test in 8 of 19 studies. Activity-specific tasks included "get up and go" (GUG) [33], "timed get up and go" (TUG) [42], "sit-to-stand" test [34], perturbed walk [33], the functional independence measure [23], "Fugl-Meyer assessment of Motor Recovery after Stroke" [37] and the Barthel index [23]. Energy expenditure by the user was assessed by indirect calorimetry [8,28,31], oxygen consumption, heart rate and respiratory rate [23]. The movement of the users was captured in eight studies with optical motion capture systems using reflective markers $[8,26,27,30,31,37,40,42]$. Ground reaction forces, plantar pressure and balance were measured using a plantar foot pressure system [36] (one study), force plates [26,27,37,39] (four studies) and instrumented treadmills [31,40,42] (three studies) to analyze the physical interaction between the exosuit user and the ground. Balance was measured with the Berg Balance Scale [23] and Biodex Balance System [36]. Commercial systems for gait measurement, Gaitrite [53] and Optogait [54], were used to measure gait spatio-temporal parameters such as gait speed, cadence, step length, stride length and swing time $[23,34,35,38]$. Muscle activity in the lower extremities was measured in four studies, using surface electromyography (EMG) [31,32,41,42]. Questionnaires were used in three studies to gather data about subjective parameters via an 11-point numerical rating scale (NRS) $[33,39]$ or a custom questionnaire with rating from 0-5 [29]. Even though symptoms such as pain are difficult to measure due to their multifaceted and subjective nature [55], self-reported measures can be a reliant input in this kind of study [56]. Hence, subjective user feedback is of crucial importance for exosuit development. For soft lower-limb exosuits, a design evaluation tool (Exoscore) has been developed recently [57].

No evaluation was conducted concerning the intended environment for the exosuit. It is foreseen that exosuits can be used in different settings, such as hospitals, rehabilitation facilities, at home or outdoors. Every environment has its own set of requirements for the exosuit, which the design and development must address. Therefore, studies should include an evaluation of design requirements for the intended environments in the future. Additionally, to analyze the results of exosuit use, a study protocol should be established that not only includes gait analysis, but also balance tests and everyday tasks to reflect use in everyday conditions.

The reviewed clinical studies did not address the ergonomics of use in detail, while ergonomic factors have been treated in other studies, for example, to evaluate the fixation of an exosuit by compression $[58,59]$. Concerning ergonomics, studies mention that exosuits are better matched to the user's capabilities when compared to rigid exoskeletons [60], but no actual comparison between exosuits and rigid exoskeletons was found. A direct comparison of different systems by the same sample of subjects would provide a better picture of technical and ergonomic advantages and disadvantages, which might lead to the development of better exoskeletons and exosuits.

The outcomes of clinical evaluations of lower-limb exosuits with users suffering from mobility impairment were overall positive. Outcomes from the reviewed studies with passive exosuits included the use of braces, elastic orthoses and elastic elements. Elastic ankle-foot orthoses (AFOs) had positive effects on controlling anterior-posterior body sway [36] and improved gait in hemiplegic users with spastic foot equinus [32]. Additionally, elastic AFOs were shown to improve velocity, cadence, step length, stride length and single-limb support in stroke patients [34], while varying the stiffness of ankle-foot orthoses had only a minimal effect on walking performance [27]. When using an elastic knee sleeve (or soft brace), knee adduction angles, moments and impulse in users with knee arthrosis were reduced [39]. This is favorable because a high knee adduction is a risk factor for disease progression of medial knee osteoarthritis [39]. The peak of knee adduction 
moment was also diminished by incorporating an inflatable air bladder into the design of a knee brace [26]. Furthermore, soft knee braces had an immediate positive effect on pain, activity limitations, self-reported knee instability and knee confidence in osteoarthritis [33]. Stretching elastic elements over hip, knee and ankle improved gait velocity [35], cadence, step length and stride length [38] in post-stroke subjects. An intervention with the "Regent Suit" showed an improvement in gait speed and daily living activities in subjects with sub-acute stroke. In the former study, it was attributed to the elastic loading elements increasing the physical effort of the user and the proprioceptive feedback [23]. Including proprioception into the design of an exosuit is promising because it is an essential component to the motor control of the musculoskeletal system [61] and has been shown to be effective for motor function recovery in stroke [23] and other musculoskeletal diseases [62]. Hence, biofeedback or proprioception may also play a role in improving exosuit-user adaptation in the future.

Active exosuits were able to increase the propulsion [8,37], walk distance [28] and maximum walking speeds [29], improve ground clearance during swing [8,41] and immediately reduce hip hiking and circumduction, used to advance the paretic limb [30] in stroke patients during gait. It has been shown that the use of active exosuits can induce a more symmetrical body movement and reduce metabolic energy consumption during hemiparetic walking [31]. The reduction in timed up and go (TUG) execution time indicated a potential improvement in functional mobility [42]. Additionally, it was indicated that tuning assistive profiles for exosuit assistance is important, so post-stroke patients can fully exploit the exosuit assistance [40].

\subsection{Study Limitations}

In the presented review, 19 studies were identified as relevant. The evaluation process was based on the prior definition of exosuits. Even though the review was conducted thoroughly, the search in four large databases may have excluded studies that may be relevant to the topic. The number of relevant publications not included in this review was minimized by choosing a search string as inclusive as possible. The risk of bias of the studies was not calculated due to the methodological heterogeneity of the studies. However, it must be considered that none of 19 articles provided a sample size justification and only two used blinded assessors for the outcome. Studies might have been biased due to their methodology. Furthermore, studies published by the same research group were not grouped for the analysis. Therefore, it is possible that in some cases the same exosuit was represented by various studies in its different development stages.

\section{Conclusions}

The presented systematic review provides an overview of 19 relevant studies of lower-limb exosuits used by impaired patients. As indicated by the growing number of publications per year, these technologies are gaining research interest year after year. Although positive effects on movement rehabilitation are expected when using lower-limb exosuits, studies that demonstrate their clinical efficacy in neuromuscular impairments are still in their early stages.

The main conclusions of this review are presented by responding to the two research questions stated in the introduction.

\subsection{What Technologies Are Used in Lower-Limb Exosuits?}

It was found that active lower-limb exosuits used electric and pneumatic actuators to control movement, while passive exosuits used elastic materials for energy storage and release. The need for external power of active exosuits led to three out of nine active exosuits being tethered, limiting their range of mobility. For increasing autonomy and range of mobility, battery-powered systems were used in the remaining six active exosuits. The force transmission from actuator to human body joint was provided mostly by Bowden cables, permitting a light mechanical system with the motors being apart from the site of 
actuation. We suggested other materials, such as shape memory alloys or active mechanical metamaterials, as suitable materials for actuation and force transmission in future exosuits.

For the control of active exosuits, sensors are used to provide input. These sensors were commercially available force, pressure or strain sensors and inertial measurement units. Biological signals, as measured by EMG or EEG, were not used to control the exosuits. We suggest the use of EMG feedback as a viable input for the control scheme. The control schemes were automatic in active exosuits, detecting the intended movement cycle and adjusted actuators accordingly, while passive exosuits did not have an active control.

Weight and power consumption were deemed important, but not all studies reported these parameters. Particularly power consumption was not reported in any study, even though it is an important parameter for the dimensioning of the power supply system of the exosuit.

4.2. What Are the Outcomes of Clinical Evaluations of Lower-Limb Exosuits with Users Suffering from Mobility Impairment?

The reported clinical outcomes of lower-limb exosuit use were overall positive. Most lower-limb exosuits addressed one articulation, with the ankle being the prevalent joint. The exosuits were mainly used by post-stroke individuals, but also to a lesser extent by osteoarthritis and trauma patients. As future fields of application, we suggested multiple sclerosis and cerebral palsy. The used test protocols were mostly focused on gait analysis using motion tracking or direct gait measurement with specific commercial systems. Additionally, balance was assessed with balance scales and muscle activity via surface EMG. Only few studies employed questionnaires to assess subjective parameters. To gather data for the design and everyday use of exosuits, it was suggested to include activity-specific tests, the evaluation of exosuit ergonomics and analysis of the intended environment for the exosuit in the test protocol.

In all fields of application, the use of passive exosuits resulted in improved gait spa-tio-temporal parameters such as velocity, cadence, step length, stride length and single-limb support. Moreover, a diminished knee abduction moment was reported, which is important to prevent the progression of osteoarthritis. The use of active exosuits induced a more symmetrical body movement and reduced metabolic energy consumption during gait. Of all clinical studies reviewed, no studies about the long-term effects on impaired users were found. While short-term evaluations have been conducted, the future study of clinical long-term effects of exosuit use on an impaired user is important for the development of rehabilitation and assistive exosuit technology. Finally, a direct comparison between exoskeletons and exosuits is encouraged. This comparison might yield a list of technical advantages and issues of both systems and could lead to an implementation of improvements to replace a found issue of one system with a better solution found in the other.

Author Contributions: Conceptualization: M.A.K. and J.M.F.-L.; Data curation: M.A.K.; Formal analysis: M.A.K.; Funding acquisition: M.A.K. and J.M.F.-L.; Investigation: M.A.K.; Methodology: M.A.K. and J.M.F.-L.; Project administration: J.M.F.-L.; Resources: M.A.K. and J.M.F.-L.; Software: M.A.K.; Supervision: J.M.F.-L.; Validation: J.M.F.-L.; Visualization: M.A.K.; Writing—original draft: M.A.K.; Writing—review and editing: M.A.K. and J.M.F.-L. Both authors have read and agreed to the published version of the manuscript.

Funding: This research received no external funding.

Institutional Review Board Statement: Not applicable.

Informed Consent Statement: Not applicable.

Data Availability Statement: Data sharing not applicable.

Conflicts of Interest: The authors declare no conflict of interest. 


\section{References}

1. Armour, B.S.; Courtney-Long, E.A.; Fox, M.H.; Fredine, H.; Cahill, A. Prevalence and Causes of Paralysis-United States, 2013. Am. J. Public Health 2016, 106, 1855-1857. [CrossRef] [PubMed]

2. Fagerström, C.; Borglin, G. Mobility, functional ability and health-related quality of life among people of 60 years or older. Aging Clin. Exp. Res. 2010, 22, 387-394. [CrossRef]

3. Okoro, C.A.; Hollis, N.D.; Cyrus, A.C.; Griffin-Blake, S. Prevalence of Disabilities and Health Care Access by Disability Status and Type Among Adults-United States, 2016. MMWR Morb. Mortal Wkly. Rep. 2018, 67, 882-887. [CrossRef]

4. Eurostat. Ageing Europe-Looking at the Lives of Older People in the EU, Statistical Books, 20th ed.; Corselli-Nordblad, L., Strandell, H., Eds.; Publications Office of the European Union: Luxembourg, 2020; ISBN 978-92-76-21520-2.

5. Esquenazi, A.; Talaty, M. Robotics for Lower Limb Rehabilitation. Phys. Med. Rehabil. Clin. 2019, 30, 385-397. [CrossRef]

6. Herr, H. Exoskeletons and orthoses: Classification, design challenges and future directions. J. Neuroeng. Rehabil. 2009, 6, 21. [CrossRef]

7. Nycz, C.; Delph, M.; Fischer, G. Modeling and design of a tendon actuated soft robotic exoskeleton for hemiparetic upper limb rehabilitation. In Proceedings of the 37th Annual International Conference of the IEEE Engineering in Medicine and Biology Society (EMBC), Milan, Italy, 25-29 August 2015; pp. 3889-3892.

8. Awad, L.; Bae, J.; O’Donnell, K.; De Rossi, S.M.; Hendron, K.; Sloot, L.H.; Kudzia, P.; Allen, S.; Holt, K.G.; Ellis, T.D.; et al. A soft robotic exosuit improves walking in patients after stroke. Sci. Transl. Med. 2017, 9, eaai9084. [CrossRef]

9. Body Braid. Available online: https:/ / bodybraid.com (accessed on 13 June 2018).

10. SuperFlex Soft Biofidelic Actuated Exosuit. Available online: https://www.sri.com/brochures/superflex-soft-biofidelic-actuatedexosuit (accessed on 13 June 2018).

11. The ReStore ${ }^{\mathrm{TM}}$ Sof Exo-Suit. ReWalk-More Than Walking. Available online: https://rewalk.com/restore-exo-suit/ (accessed on 1 October 2020).

12. Shi, D.; Zhang, W.; Zhang, W.; Ding, X. A Review on Lower Limb Rehabilitation Exoskeleton Robots. Chin. J. Mech. Eng. 2019, 32, 74. [CrossRef]

13. Pamungkas, D.S.; Caesarendra, W.; Soebakti, H.; Analia, R.; Susanto, S. Overview: Types of Lower Limb Exoskeletons. Electronics 2019, 8, 1283. [CrossRef]

14. Jain, A.; Jain, K. Soft exosuit-A review. Int. Rob. Auto. J. 2020, 6, 99-101.

15. Crowell, H.P.; Park, J.H.; Haynes, C.A.; Neugebauer, J.M.; Boynton, A.C. Design, Evaluation, and Research Challenges Relevant to Exoskeletons and Exosuits: A 26-Year Perspective From the U.S. Army Research Laboratory. IISE Trans. Occup. Ergon. Hum. Factors 2019, 7, 199-212. [CrossRef]

16. Masia, L.; Hussain, I.; Xiloyannis, M.; Pacchierotti, C.; Cappello, L.; Malvezzi, M.; Spagnoletti, G.; Antuvan, C.W.; Binh Khanh, D.; Pozzi, M.; et al. Soft wearable assistive robotics: Exosuits and supernumerary limbs. In Wearable Exoskeleton Systems: Design, Control and Applications; Bai, S., Virk, G.S., Sugar, T.G., Eds.; IET: Stevenage, UK, 2018; pp. 219-254.

17. Totaro, M.; Natali, C.D.; Bernardeschi, I.; Ortiz, J.; Beccai, L. Mechanical Sensing for Lower Limb Soft Exoskeletons: Recent Progress and Challenges. Adv. Exp. Med. Biol. 2019, 1170, 69-85.

18. Chen, B.; Ma, H.; Qin, L.; Gao, F.; Chan, K.M.; Law, S.W.; Qin, L.; Liao, W.H. Recent developments and challenges of lower extremity exoskeletons. J. Orthop. Translat. 2016, 5, 26-37. [CrossRef] [PubMed]

19. National Institutes of Health. Study Quality Assessment Tools. Quality Assessment Tool for Observational Cohort and CrossSectional Studies. Available online: https://www.nhlbi.nih.gov/health-topics/study-quality-assessment-tools (accessed on 1 October 2020).

20. Moher, D.; Liberati, A.; Tetzlaff, J.; Altman, D.G. PRISMA Group Preferred Reporting Items for Systematic Reviews and Meta-Analyses: The PRISMA Statement. PLoS Med. 2009, 6, e1000097. [CrossRef]

21. Space Meets Medicine at MEDICA. 2005. Available online: http://www.esa.int/Our_Activities/Human_Spaceflight/Business/ Space_meets_medicine_at_MEDICA_20052 (accessed on 19 June 2018).

22. Kozlovskaya, I.; Grigoriev, A. Russian system of countermeasures on board of the International Space Station (ISS): The first results. Acta Astronaut. 2004, 55, 233-237. [CrossRef] [PubMed]

23. Monticone, M.; Ambrosini, E.; Ferrante, S.; Colombo, R. 'Regent Suit' training improves recovery of motor and daily living activities in subjects with subacute stroke: A randomized controlled trial. Clin. Rehabil. 2013, 27, 792-802. [CrossRef]

24. Noordzij, M.; Dekker, F.W.; Zoccali, C.; Jager, K.J. Sample size calculations. Nephron. Clin. Pract. 2011, 118, c319-c323. [CrossRef] [PubMed]

25. Gross, C.; Mallory, R.; Heiat, A.; Krumholz, H. Reporting the Recruitment Process in Clinical Trials: Who Are These Patients and How Did They Get There? Ann. Intern. Med. 2002, 137, 10. [CrossRef]

26. Della Croce, U.; Crapanzano, F.; Li, L.; Kasi, P.K.; Patritti, B.L.; Mancinelli, C.; Hunter, D.J.; Stamenović, D.; Harvey, W.F.; Bonato, P. A Preliminary Assessment of a Novel Pneumatic Unloading Knee Brace on the Gait Mechanics of Patients with Knee Osteoarthritis. PMER 2013, 5, 816-824.

27. Harper, N.; Esposito, E.; Wilken, J.; Neptune, R. The influence of ankle-foot orthosis stiffness on walking performance in individuals with lower-limb impairments. Clin. Biomech. 2014, 29, 877-884. [CrossRef]

28. Awad, L.; Kudzia, P.; Revi, D.; Ellis, T.; Walsh, C. Walking Faster and Farther With a Soft Robotic Exosuit. Implications for Post-Stroke Gait Assistance and Rehabilitation. IEEE Open J. Eng. Med. Biol. 2020, 1, 108-115. [CrossRef] 
29. Awad, L.; Esquenazi, A.; Francisco, G.; Nolan, K.; Jayaraman, A. The ReWalk ReStore ${ }^{\mathrm{TM}}$ soft robotic exosuit: A multi-site clinical trial of the safety, reliability, and feasibility of exosuit-augmented post-stroke gait rehabilitation. J. Neuroeng Rehabil. 2020, 17, 80. [CrossRef] [PubMed]

30. Awad, L.; Bae, J.; Kudzia, P.; Long, A.; Hendron, K.; Holt, K.G.; O’Donnell, K.; Ellis, T.D.; Walsh, C.J. Reducing Circumduction and Hip Hiking During Hemiparetic Walking Through Targeted Assistance of the Paretic Limb Using a Soft Robotic Exosuit. Am. J. Phys. Med. Rehabil. 2017, 96, S157-S164. [CrossRef] [PubMed]

31. Bae, J.; Awad, L.; Long, A.; O’Donnell, K.; Hendron, K.; Holt, K.G.; Ellis, T.D.; Walsh, C.J. Biomechanical mechanisms underlying exosuit-induced improvements in walking economy after stroke. J. Exp. Biol. 2018, 221, jeb168815. [CrossRef] [PubMed]

32. Boudarham, J.; Pradon, D.; Roche, N.; Bensmail, D.; Zory, R. Effects of a dynamic-ankle-foot orthosis (Liberté ${ }^{\circledR}$ ) on kinematics and electromyographic activity during gait in hemiplegic patients with spastic foot equinus. NeuroRehabilitation 2014, 35, 369-379. [CrossRef] [PubMed]

33. Cudejko, T.; van der Esch, M.; van der Leeden, M.; van den Noort, J.C.; Roorda, L.D.; Lems, W.; Twisk, J.; Steultjerns, M.; Woodburn, J.; Harlaar, J.; et al. The immediate effect of a soft knee brace on pain, activity limitations, self-reported knee instability, and self-reported knee confidence in patients with knee osteoarthritis. Arthritis Res. Ther. 2017, 19, 260. [CrossRef] [PubMed]

34. Daher, N.; Lee, S.; Yang, Y. Effects of elastic band orthosis (aider) on balance and gait in chronic stroke patients. Phys. Ther. Rehabil. Sci. 2013, 2, 81-86. [CrossRef]

35. Hwang, Y.; Yoo, W.; An, D. Effects of the Elastic Walking Band on gait in stroke patients. NeuroRehabilitation 2013, 32, 317-322. [CrossRef] [PubMed]

36. Kim, J.H.; Sim, W.S.; Won, B.H. Effectiveness of elastic band-type ankle-foot orthoses on postural control in poststroke elderly patients as determined using combined measurement of the stability index and body weight-bearing ratio. Clin. Interv. Aging 2015, 10, 1839-1847. [CrossRef] [PubMed]

37. Kwon, J.; Park, J.; Ku, S.; Jeong, Y.; Paik, N.; Park, Y. A Soft Wearable Robotic Ankle-Foot-Orthosis for Post-Stroke Patients. IEEE Robot Autom. Lett. 2019, 4, 2547-2552. [CrossRef]

38. Lee, S.; Cynn, H.; Yi, C.; Yoon, T.; Lee, J. Wearable tubing assistive walking device immediately enhances gait parameters in subjects with stroke: A randomized controlled study. NeuroRehabilitation 2017, 40, 99-107. [CrossRef]

39. Schween, R.; Gehring, D.; Gollhofer, A. Immediate Effects of an Elastic Knee Sleeve on Frontal Plane Gait Biomechanics in Knee Osteoarthritis. PLoS ONE 2015, 10, e0115782. [CrossRef] [PubMed]

40. Siviy, C.; Bae, J.; Baker, L.; Porciuncula, F.; Baker, T.; Ellis, T.D.; Awad, L.N.; Walsh, C.J. Offline Assistance Optimization of a Soft Exosuit for Augmenting Ankle Power of Stroke Survivors During Walking. IEEE Robot Autom. Lett. 2020, 5, 828-835. [CrossRef]

41. Sloot, L.; Bae, J.; Baker, L.; O’Donnell, K.; Menard, N.; Porciuncula, F.; Choe, D.; Ellis, T.; Awad, L.; Walsh, C. O 089—A soft robotic exosuit assisting the paretic ankle in patients post-stroke: Effect on muscle activation during overground walking. Gait Posture 2018, 18, 30881-30886. [CrossRef] [PubMed]

42. Sridar, S.; Qiao, Z.; Rascon, A.; Biemond, A.; Beltran, A.; Maruyama, T.; Kwasnica, C.; Polygerinos, P.; Zhang, W. Evaluating Immediate Benefits of Assisting Knee Extension With a Soft Inflatable Exosuit. IEEE Trans. Med. Robot Bionics. 2020, 2, 216-225. [CrossRef]

43. Jin, X.; Prado, A.; Agrawal, S. Retraining of Human Gait-Are Lightweight Cable-Driven Leg Exoskeleton Designs Effective? IEEE Trans. Neural Syst. Rehabil. Eng. 2018, 26, 847-855. [CrossRef] [PubMed]

44. Park, S.J.; Park, C.H. Suit-type Wearable Robot Powered by Shape-memory-alloy-based Fabric Muscle. Sci. Rep. 2019, 9, 9157. [CrossRef]

45. Copaci, D.; Flores, A.; Rueda, F.; Alguacil, I.; Blanco, D.; Moreno, L. Wearable elbow exoskeleton actuated with shape memory alloy. In Converging Clinical and Engineering Research on Neurorehabilitation II; Ibáñez, J., González-Vargas, J., Azorín, J.M., Akay, M., Pons, J.L., Eds.; Springer: Berlin, Germany, 2017; pp. 477-481.

46. Pishvar, M.; Harne, R. Foundations for Soft, Smart Matter by Active Mechanical Metamaterials. Adv. Sci. 2020, 7, 2001384. [CrossRef] [PubMed]

47. Kos, A.; Umek, A.; Tomazic, S. Biofeedback in sport: Challenges in real-time motion tracking and processing. In Proceedings of the IEEE 15th International Conference on Bioinformatics and Bioengineering (BIBE), Belgrade, Serbia, 2-4 November 2015; pp. $1-4$.

48. Contreras-Vidal, J.L.; Bhagat, N.A.; Brantley, J.; Cruz-Garza, J.G.; He, Y.; Manley, Q.; Nakagome, S.; Nathan, K.; Tan, S.H.; Zhu, F.; et al. Powered exoskeletons for bipedal locomotion after spinal cord injury. J. Neural. Eng. 2016, 13, 31001. [CrossRef]

49. Ferris, D.; Sawicki, G.; Daley, M. A physiologist's perspective on robotic exoskeletons for human locomotion. Int. J. Humanoid Robot. 2007, 4, 507-528. [CrossRef]

50. Di Russo, F.; Berchicci, M.; Perri, R.; Ripani, F.R.; Ripani, M. A Passive Exoskeleton Can Push Your Life Up: Application on Multiple Sclerosis Patients. PLoS ONE 2013, 8, e77348.

51. Reyes, F.; Niedzwecki, C.; Gaebler-Spira, D. Technological Advancements in Cerebral Palsy Rehabilitation. Phys. Med. Rehabil. Clin. 2020, 31, 117-129. [CrossRef] [PubMed]

52. He, Y.; Eguren, D.; Luu, T.; Contreras-Vidal, J. Risk management and regulations for lower limb medical exoskeletons: A review. Med. Devices 2017, 10, 89-107. [CrossRef] [PubMed]

53. Gaitrite. Available online: https://www.gaitrite.com/ (accessed on 4 June 2019).

54. Microgate OptoGait. Available online: http:/ / www.optogait.com/ (accessed on 17 October 2020). 
55. Younger, J.; McCue, R.; Mackey, S. Pain outcomes: A brief review of instruments and techniques. Curr. Pain Headache Rep. 2009, 13, 39-43. [CrossRef] [PubMed]

56. Allen, D. Validity and Reliability of the Movement Ability Measure: A Self-Report Instrument Proposed for Assessing Movement Across Diagnoses and Ability Levels. Phys. Ther. 2007, 87, 899-916. [CrossRef] [PubMed]

57. Shore, L.; Power, V.; Hartigan, B.; Schülein, S.; Graf, E.; de Eyto, A.; O'Sullivan, L. Exoscore: A Design Tool to Evaluate Factors Associated With Technology Acceptance of Soft Lower Limb Exosuits by Older Adults. Human Factors 2019, 62, 391-410. [CrossRef]

58. Yandell, M.; Ziemnicki, D.; McDonald, K.; Zelik, K. Characterizing the comfort limits of forces applied to the shoulders, thigh and shank to inform exosuit design. PLoS ONE 2020, 15, e228536. [CrossRef]

59. Kermavnar, T.; O'Sullivan, K.; Casey, V.; de Eyto, A.; O'Sullivan, L. Circumferential tissue compression at the lower limb during walking, and its effect on discomfort, pain and tissue oxygenation: Application to soft exoskeleton design. Appl. Ergon. 2020, 86, 103093. [CrossRef]

60. Haufe, F.; Kober, A.; Schmidt, K.; Sancho-Puchades, A.; Duarte, J.E.; Wolf, P.; Riener, R. User-driven walking assistance: First experimental results using the MyoSuit. In Proceedings of the IEEE 16th International Conference on Rehabilitation Robotics (ICORR), Toronto, ON, Canada, 24-28 June 2019; pp. 944-949.

61. Riemann, B.; Lephart, S. The Sensorimotor System, Part II: The Role of Proprioception in Motor Control and Functional Joint Stability. J. Athl. Train. 2002, 37, 80-84.

62. Aman, J.; Elangovan, N.; Yeh, I.; Konczak, J. The effectiveness of proprioceptive training for improving motor function: A systematic review. Front. Hum. Neurosci. 2015, 8, 1075. [CrossRef] 